\title{
Is publication bias present in gastroenterological research? An analysis of abstracts presented at an annual congress
}

\author{
Chase Meyer ${ }^{\text {Corresp., }}{ }^{1}$, Kaleb Fuller ${ }^{1}$, Jared Scott ${ }^{1}$, Matt Vassar ${ }^{1}$ \\ ${ }^{1}$ Oklahoma State University College of Osteopathic Medicine, Tulsa, Oklahoma, United States \\ Corresponding Author: Chase Meyer \\ Email address: chase.meyer@okstate.edu
}

Background Publication bias is the tendency of investigators, reviewers, and editors to submit or accept manuscripts for publication based on their direction or strength of findings. In this study, we investigated if publication bias was present in gastroenterological research by evaluating abstracts at Americas Hepato-Pancreato-Biliary Congresses from 2011 to 2013. Methods We searched Google, Google Scholar, and PubMed to locate the published reports of research described in these abstracts. If a publication was not found, a second investigator searched to verify nonpublication. If abstract publication status remained undetermined, authors were contacted regarding reasons for nonpublication. For articles reaching publication, the $P$ value, study design, time to publication, citation count, and journals in which the published report appeared were recorded. Results Our study found that of 569 abstracts presented, 297 (52.2\%) reported a $P$ value. Of these, 254 (85.5\%) contained $P$ values supporting statistical significance. The abstracts reporting a statistically significant outcome were twice as likely to reach publication than abstracts with no significant findings (OR $2.10,95 \% \mathrm{Cl}$ 1.06-4.14). Overall, 243 (42.7\%) abstracts reached publication. The mean time to publication was 14 months and a median time of 9 months. Conclusion In conclusion, we found evidence for publication bias in gastroenterological research. Abstracts with significant $P$ values had a higher probability of reaching publication. More than half of abstracts presented from 2011 to 2013 failed to reached publication. Readers should take these finding into consideration when reviewing medical literature. 


\section{Title page}

2

3 Is publication bias present in gastroenterological research? An analysis of abstracts presented at

4 an annual congress

5

6 Chase Meyer ${ }^{1}$

$7 \quad$ Kaleb Fuller ${ }^{1}$

8 Jared Scott ${ }^{1}$

9 Matt Vassar ${ }^{1}$

10

11

$12{ }^{1}$ Oklahoma State University College of Osteopathic Medicine, Tulsa, OK

13

14

15 Corresponding author: Chase Meyer, Oklahoma State University - Center for Health Sciences,

161111 W 17th St Tulsa, 74107, United States. Phone: 918-582-1972 Email:

17 Chase.Meyer@okstate.edu

18

19

20 Word count $=3033$ words

21

22

23

\section{Abstract}




\section{Background}

27 Publication bias is the tendency of investigators, reviewers, and editors to submit or accept

28 manuscripts for publication based on their direction or strength of findings. In this study, we

29 investigated if publication bias was present in gastroenterological research by evaluating

30 abstracts at Americas Hepato-Pancreato-Biliary Congresses from 2011 to 2013.

\section{Methods}

33 We searched Google, Google Scholar, and PubMed to locate the published reports of research

34 described in these abstracts. If a publication was not found, a second investigator searched to

35 verify nonpublication. If abstract publication status remained undetermined, authors were

36 contacted regarding reasons for nonpublication. For articles reaching publication, the $P$ value,

37 study design, time to publication, citation count, and journals in which the published report

38 appeared were recorded.

\section{Results}

41 Our study found that of 569 abstracts presented, 297 (52.2\%) reported a $P$ value. Of these, 254

$42 \quad(85.5 \%)$ contained $P$ values supporting statistical significance. The abstracts reporting a

43 statistically significant outcome were twice as likely to reach publication than abstracts with no

44 significant findings (OR 2.10, 95\% CI 1.06-4.14). Overall, 243 (42.7\%) abstracts reached

45 publication. The mean time to publication was 14 months and a median time of 9 months.

\section{Conclusion}


48 In conclusion, we found evidence for publication bias in gastroenterological research. Abstracts 49 with significant $P$ values were more frequently published than those with negative results. More 50 than half of abstracts presented from 2011 to 2013 failed to reached publication. Readers should 51 take these findings into consideration when reviewing medical literature.

52

53 


\section{Introduction}

55

56 The practice of evidence-based medicine integrates clinical expertise with the best available

57 clinical research evidence.(Sackett et al. 1996) This movement promotes the use of high-quality

58 clinical research into clinical decision making.(Masic, Miokovic, and Muhamedagic 2008) If

59 treatment decisions are to truly be evidence based, it is necessary that the literature accurately

60 reflect an intervention's effectiveness.(Dickersin 1990) This information is thwarted, however,

61 when research regarding efficacy does not reach publication.

62

63 Publication bias is one such reason why studies fail to be published. Publication bias is the

64 tendency of investigators, reviewers, and editors to submit or accept manuscripts for publication

65 based on their direction or strength of findings.(Dickersin 1990) A substantial body of evidence

66 supports that studies reporting negative (nonsignificant) findings are less likely to be

67 published.(Fanelli 2010; Easterbrook et al. 1991) The implications of publication bias are far

68 reaching for clinical decision making owing to the possibility of overestimated treatment effects.

69 For example, several meta-analyses have re-evaluated the efficacy and safety of antidepressants

70 and determined that their therapeutic value has been overestimated when considering data used

71 from unpublished studies.(Turner et al. 2008; Eyding et al. 2010; Barbui, Furukawa, and Cipriani

72 2008; Whittington et al. 2004) Interestingly, while publication bias has been widely discussed in

73 many areas of medicine such as cancer(Harris et al. 2010; Saeed et al. 2011; Paulson et al. 2011;

74 Salami and Alkayed 2013; Sartor, Peterson, and Woolf 2003; Takeda et al. 2008) and

75 anesthesiology(Chong et al. 2016; De Oliveira et al. 2012; Lim et al. 2016; Sukhal et al. 2017; P.

76 M. Jones 2016; Hedin et al. 2016), this important issue has received limited attention in 
77 gastroenterology with mixed results.(Timmer et al. 2002; Shaheen et al. 2000; Eloubeidi, Wade,

78 and Provenzale 2001) One example of the implications of publication bias concluded that the

79 incidence of Barrett's esophagus may be overestimated due to publication bias.(Shaheen et al.

80 2000) If the incidence is lower than previously assumed, there might be an overemphasis on the

81 benefits of costly screening programs, leading to a loss of resources.

82

83 Publication bias may also arise during scientific meetings. Organizations hold scientific meetings

84 to allow researchers to come together to discuss new and ongoing topics related to their field of

85 interest through oral and poster presentations of original abstracts. Because of the competitive

86 publication process, abstracts that are presented likely represent strong research that may

87 influence the current literature.(Frank et al. 2017) However, not all presentations will be

88 published, and non-publication of findings may be harmful to patients, may result in unnecessary

89 duplication of efforts, may contribute to research waste, and may prevent results from being

90 included in systematic reviews.(Durinka et al. 2016)

91

92 In this study, we measured the publication rate of abstracts presented at Americas Hepato-

93 Pancreato-Biliary Association (AHPBA) Congresses and established whether publication bias

94 may have occurred between abstract presentation and publication. We also evaluated the length

95 of time to publication and which journals most frequently publish AHPBA abstracts. For

96 unpublished abstracts, we contacted authors to determine the reason for nonpublication.

97

98 Methods

99 
100 Oversight and Reporting

101

102 This study did not meet the regulatory definition of human subjects research as defined in 45

103 CFR 46.102(d) and (f) of the Department of Health and Human Services' Code of Federal

104 Regulations and therefore was not subject to Institutional Review Board oversight. We applied

105 relevant Statistical Analyses and Methods in the Published Literature guidelines for reporting 106 descriptive statistics.

107

108 Locating Conference Abstracts

109

110 We located the AHPBA abstracts from 2011 to 2013 through the AHPBA website.("AHPBA -

111 Annual Meeting - Past Meeting Archives" n.d.) We selected this time period based on previous

112 literature describing the need to allow adequate time for a conference abstract to be

113 published.(Durinka et al. 2016) After locating the AHPBA abstracts we began the search

114 process.

115

116 Search Strategy for Published Manuscripts of Conference Abstracts

117

118 Using a predefined search algorithm, we attempted to locate the published report of conference

119 abstracts (Figure 1). The search algorithm was developed by two investigators (JS and MV) and 120 pilot tested on 25 abstracts. We assessed the optimal order in which to search databases (for

121 example, Google first, Google Scholar second, and PubMed third). We also varied the searches

122 by using combinations of keywords and author names and used full title searches to determine 
123 which strategy would most precisely locate published reports. Ultimately, our search was

124 completed using three databases: PubMed, Google Scholar, and Google. One investigator (CM)

125 first searched these three databases using the full conference abstract title. If this strategy failed, 126 this investigator performed searches using an author's last name and keywords from the abstract.

127 When CM could not locate a published report, a second investigator (KF) repeated the search 128 strategy.

129

130 If the second investigator (KF) could not locate the published report, CM sent a standardized 131 email to an author of the conference abstract (see Appendix 1). This email gave authors the opportunity to comment whether the study had reached publication and provide the reference for the publication. If the author indicated the report was not published, abstract authors were asked to provide a reason for nonpublication. Our standardized response options for nonpublication were based on a systematic review by Song et al.(Song, Loke, and Hooper 2014) which analyzed 38 survey reports on investigator-reported reasons for nonpublication.

For studies that were not found to be published and also contained negative findings, we also searched for them on Faculty of 1000 (F1000), BioMed Central (which includes the archives of the Journal of Negative Results in Biomedicine), and Cureus, as these sources publish studies 141 with negative findings.

\section{Data Collection}


146 Our search dates ranged from June 13, 2017 to June 20, 2017. Once a published study that was

147 thought to be a conference abstract was located, we compared the author list, methods, and

148 results between them. If at least two of the following criteria were met, we considered the

149 abstract published: (1) results in both reports matched; (2) the methodology was similar; and (3)

150 the first author of the conference abstract was included in the author list of the published study.

152 Data were extracted from the published studies by CM using a Google form. The following

153 information was extracted: publication title, institution of first author, date submitted to journal

154 (when available), date accepted for publication (when available), date of in print publication

155 (when available), date of online publication (when available), sample size (when available),

156 journal name, number of citations, and whether there was a significant outcome $(P<0.05)$. The

157 time to publication was calculated based on the number of months between the first date of the

158 conference and the publication date in print or online, whichever occurred first. Descriptive

159 statistics are reported as both means and medians. The reporting of means allows for

160 interpretation of our findings in the context of other studies. Medians are reported due to the

161 non-normal nature of the time to publication and citation count variables. A Mann Whitney $\mathrm{U}$

162 test was used to evaluate for differences on citation count between studies with positive and

163 negative results. For this analysis, we included sample size and study design as potential

164 predictors of publication. Logistic regression was used to evaluate the associations of sample size

165 and study design with publication. We classified abstracts according to study design, which

166 included such designs as: cohort studies, case studies, and randomized controlled trials. For study

167 design, the investigators retained all study designs that represented at least $10 \%$ of abstract 
168 presentations for stability of the regression coefficients. Data analyses were performed using 169 Microsoft Excel and Stata 13.1.

170

\section{Results}

172 A total of 12 abstracts were found to be published before presentation and were therefore

173 excluded from this study. A $P$ value was reported in 297 (52.2\%) of 569 abstract presentations.

174 Of those with a reported $P$ value, $254(85.5 \%)$ reported significant outcomes. Of the 254 that 175 reported a significant outcome, $139(54.7 \%)$ went on to reach publication. Of the 41 abstracts 176 that reported negative outcomes, $15(36.6 \%)$ went on to reach publication. No abstracts that 177 reported only negative outcomes were found to be published on F1000, BioMed Central, or 178 Cureus. Abstracts with at least one significant outcome were twice as likely to reach publication 179 than abstracts with no significant findings (OR 2.10; 95\% CI (1.06-4.14). The most common 180 study design was retrospective analysis, with 313 abstracts. Of these, 150 (47.9\%) reached 181 publication. The least common study design was the randomized controlled trial with 3 abstracts;

182 however, all reached publication. Full study design results can be found in Table 1.

184 From 2011 to 2013 there were 569 abstract presentations, of which 243 (42.7\%) reached 185 publication (Figure 2). The mean time to publication was 14.0 months and a median time of 9 186 months. For 2011, 79 of 168 (47\%) abstracts reached publication, with an mean time of 12.5 187 months and a median time of 7 months. For 2012, 89 of $201(44.3 \%)$ abstracts reached 188 publication, with an mean time of 14.8 months and a median time of 12 months. For 2013, 75 of $189200(37.5 \%)$ abstracts reached publication, with an mean time of 14.5 months and a median time 190 of 11 months. A graph displaying cumulative time to publication is presented in Figure 3. For 
191 abstracts with significant findings, the mean time to publication was 12.1 months and a median

192 time of 8 months. For abstracts with negative findings, the mean time to publication was 13.6

193 months and a median time of 8 months.

194

195 Citation counts were not significantly different between studies with negative results (Median =

196 12, Interquartile range (IQR) 8-28) and studies with positive results (Median = 13, IQR 3-74; Z=-

$197.34, \mathrm{P}>.05$ ). Results from logistic regression indicated that sample size (OR 1.00, 95\% CI: .99-

198 1.00) retrospective study design (OR .90, 95\% CI: .46-1.76), or case reports (OR 4.70, 95\% CI:

$199.61-36.35$ ) were not predictive factors of publication status (model $\square^{2}=4.91, \mathrm{p}>.05$ ). Other

200 study designs were encountered too infrequently to include in this analysis.

201

202 Fifty-nine journals published abstracts presented at the AHPBA congresses from 2011 to 2013

203 (Table 2). There were 8 journals that published 5 or more full-text articles from the abstract

204 presentations, accounting for $70 \%$ of publications. The most frequent journal in which abstracts

205 were published was the conference's own journal, HPB, with 115 of the 243 publications

206 (47.3\%). Other notable journals included Annals of Surgical Oncology 14 of 243 (5.7\%) and the

207 Journal of Gastrointestinal Surgery 12 of 243 (4.9\%). Table 2 also includes data on the

208 distribution of positive and negative results published in these journals.

209

210 Some 326 abstract presentations could not be found published as full papers. Email addresses

211 were obtained for 298 authors of these abstracts. Twenty-eight authors of the abstract

212 presentations could not be associated with an email address. Additionally, 42 emails were

213 returned as invalid addresses. Thirty-four authors (34/256, 13.3\%) responded to emails. Of these 
21434,10 authors provided information that their presentation was published, while 24 reported that

215 it never reached publication. The most common reasons for not reaching publication were lack of

216 time (7), lack of manpower (4), in preparation or under review (4), and results negative or not

217 important (3).

218

219 Discussion

220

221 Our study, like others before it, revealed that investigations with at least one statistically

222 significant outcome had a higher probability of reaching publication than those with insignificant 223 or null findings.(Sally Hopewell et al. 2009; Tang et al. 2014) Furthermore, our findings on 224 study design are consistent with Ball et al. for abstracts presented from 2005 to 2015 at the 225 AHPBA.(Ball, Dixon, and Vollmer 2016)

226

227 It could cogently be argued that $P$ values are misused in the medical literature. For example, 228 Amrhein et al. reminds us that the dichotomization of outcomes into significant and non229 significant may contribute to irreproducibility and that data dredging, p-hacking, and publication 230 bias should be addressed by the elimination of significance thresholds.(Amrhein, Korner231 Nievergelt, and Roth 2017) The majority of abstracts in our sample were retrospective in design 232 not adequately powered, well-conducted randomized trials. This misuse has been attributed to 233 the mistaken understanding that $P$ values are, "simple, reliable, and objective triage tools for 234 separating the true and important from the untrue or unimportant” (Mark, Lee, and Harrell 2016). 235 Alternatives to $P$ value reporting are increasing in popularity. Reporting the effect size (for 236 interpretation of clinical significance) and its confidence interval (for interpretation of the 
237 precision of the effect estimate) are advocated by the American Statistical Association and many

238 journals (Piccirillo 2016). Hence, the study design should carefully be considered when

239 determining the appropriateness of calculating and reporting $P$ values. The American Statistical

240 Association's recent position statement on $P$ values (Wasserstein and Lazar 2016) is an excellent

241 starting point for understanding issues related to the misuse of $P$ values.

242

243 Furthermore, results of our study could be attributed, in part, to the misapplication of statistical

244 analysis to underpowered studies. Publication bias, selective data analysis, and selective

245 reporting of outcomes are more likely to affect underpowered studies.(Button et al. 2013)

246 Additionally, editors and reviewers may be more likely to reject underpowered, negative studies

247 owing to their perception of being inconclusive or uninformative.(Evangelou et al. 2012)

248

249 Finally, a large body of evidence has focused on the consequences of publication bias pertaining 250 to randomized trials. In a systematic review of such trials, the omission of unpublished results 251 may alter pooled effect estimates. Oftentimes, the pooled effect estimate is altered to make the 252 intervention to appear more favorable. In our study, the most common study design was a 253 retrospective study. The effects of publication bias on these studies is still important, as 254 epidemiological outcomes, such as prevalence and incidence, may be misestimated and 255 correlational analyses may indicate inaccurate associations between clinical variables.

257 The publication rate of abstracts presented at the AHPBA from 2011 to 2013 was $42.7 \%$. This

258 rate is higher than what was found for the 2007 to 2009 congresses (33.4\%).(Durinka et al. 2016)

259 The rate of $42.7 \%$ is similar to the $44.5 \%$ rate reported by Scherer et al.(R. W. Scherer,

260 Langenberg, and von Elm 2007) in a systematic review of publication rates for 79 different 
261 biomedical conferences. In the context of other gastroenterology conferences, the $42.7 \%$ rate of

262 publication was not the lowest. Prendergast et al. found that the British Society of

263 Gastroenterology (BSG) had a rate of $17.4 \%$ in 2005 and Raju et al. found a rate of $30.9 \%$ for

264 abstracts at the United European Gastroenterology week (UEGW).(Prendergast et al. 2013; Raju

265 et al. 2017) Reasons for not reaching publication were consistent with previous studies and most

266 commonly pertained to lack of time, manpower, or negative results.(Pierson 2004)-(Roberta W.

267 Scherer et al. 2015) Another consideration is that unpublished research may have never been

268 submitted to a journal for review. Implications for not publishing are far reaching. With over

$269 \$ 240$ billion spent on health research each year, it is ideal to publish research to avoid

270 unnecessary duplication, make data accessible, and prioritize future research.(Wolfenden et al.

271 2015) Additionally, not publishing has been shown to decrease the likelihood of future patient

272 volunteers.(C. W. Jones et al. 2016)

273 The length of time to publication in our investigation (mean: 14 months, median: 9 months) is

274 favorable in comparison with BSG's mean time of 18.6 months and the same as the mean 14

275 months reported by Durinka et al. from 2007 to 2009. (Durinka et al. 2016), (Prendergast et al. 2013)

276 Furthermore, the AHPBA's median time to publication compares favorably to abstracts

277 presented at other gastroenterology conferences.(Raju et al. 2017; Timmer et al. 2002) A

278 Cochrane review found that the length of time for publication can be influenced by publication

279 bias.(S. Hopewell et al. 2007) This review found that positive results were more likely to be

280 published more quickly than those with null or negative results. Studies published earlier are

281 made available to clinicians sooner and therefore have clinical important implications to patient

282 care. For example, the quicker publication of positive findings may result in systematic reviews

283 overestimating treatment effects.(R. W. Scherer, Langenberg, and von Elm 2007) Furthermore, 
284 publication bias led to the widespread promotion of oseltamivir during pandemic seasons in 2005 285 and 2009.(Gupta, Meenu, and Mohan 2015) A systematic review highlighted this high risk of 286 reporting and publication bias in trials assessing oseltamivir, finding limited evidence for its 287 effectiveness in reducing symptoms, data unable to assess its effects on complications or 288 transmission, and an increase in adverse side effects.(Jefferson et al. 2014)

289 Publication bias is a cause for concern in the medical literature, as studies are often published 290 due to the large magnitude effect sizes reported by investigators. Such effects are not likely 291 reproducible in subsequent studies.(Baker and Dolgin 2017) Furthermore, systematic review 292 efforts are often hindered when only data from published studies are available for inclusion in 293 estimating summary effect estimates. For these reasons, it is important that action be taken to 294 limit publication bias in the gastroenterology literature. To accomplish this aim, we propose that 295 the following steps be taken:

1. Gastroenterology journals should pilot test, and work toward the adoption of, a two-stage peer review process in which the first stage is to evaluate the study on the methodological rigor of the study design before the outcomes of the study are known.

2. Gastroenterology journals and conferences need to place value on null and negative findings, encourage authors to submit their research regardless of the nature or direction of their findings.

3. Gastroenterology journals should consider including a negative results section of their journals as has been done in other medical fields.(Dirnagl and Lauritzen 2010)

306 We note the following limitations. First, while extensive measures were taken to determine the 
307 publication status of each abstract, it is possible that some were missed which could affect the

308 results of this study. Changes in authorship, such as adding additional authors or rearranging the

309 authorship order make matching abstracts with the published report more difficult. Changes to

310 the title poses the same challenge. It is also possible that authors submitted interim results to the

311 Congress yet published the final results, leading to incongruent aggregate outcomes and sample

312 sizes. Other complicating factors include 2 abstracts being combined to form a single publication

313 or a single abstract being parsed into multiple publications. Additionally, by excluding abstracts

314 that did not report a $P$ value from certain analyses could result in a bias in the reported estimate

315 of incidence of significant results included in the studied publications. However, we feel

316 confident that the abstracts identified as published by our search strategy are truly published

317 versions of abstracts presented from 2011 to 2013 at the AHPBA annual congresses. While every

318 effort was made to find author email addresses and make contact, we were unable to find a valid

319 email address for authors of 70 presentations. Researchers only used Google, Google Scholar, 320 and PubMed to find publications. Studies indexed in other databases that do not connect via

321 Google may have been missed. However, given the exhaustive search and the efforts to email the

322 authors, the number of omissions is likely very small. Given that $84 \%$ of abstracts were

323 published in less than 24 months, our search interval was likely adequate. Therefore, we caution

324 readers that our finding should be considered a lower bound estimate of the publication rate. 325

326 Conclusion

327

328 In conclusion, we found publication bias in the field of gastroenterological research. Abstracts

329 with significant $P$ values were more frequently published than those with negative results. In 
330 addition, more than half of abstracts presented at the 2011 to 2013 AHPBA conferences failed to

331 reached publication. Readers should take these finding into consideration when reviewing 332 medical literature.

333

334

335

336

337

338

339

340

341 
342

343

344

345

346

347

348

349

350

351

352

353

354

355

356

357

358

359

360

361

362

363

364

365

366

367

368

369

370

371

372

373

374

375

376

377

378

379

380

381

382

383

384

385

386

\section{References}

“AHPBA - Annual Meeting - Past Meeting Archives.” n.d. Accessed July 2, 2017. https://www.ahpba.org/meeting/past-meeting-archives.phtml.

Amrhein, Valentin, Fränzi Korner-Nievergelt, and Tobias Roth. 2017. "The Earth Is Flat (p> 0.05): Significance Thresholds and the Crisis of Unreplicable Research.” PeerJ 5. PeerJ Inc.: e3544.

Baker, Monya, and Elie Dolgin. 2017. "Cancer Reproducibility Project Releases First Results." Nature 541 (7637): 269-70.

Ball, Chad G., Elijah Dixon, and Charles M. Vollmer. 2016. "Trends in the Scientific Program of the Americas Hepato-Pancreato-Biliary Association (AHPBA) Annual Meeting over the Past Decade: The More Things Change, the More They Stay the Same." HPB: The Official Journal of the International Hepato Pancreato Biliary Association 18 (8): 697-99.

Barbui, Corrado, Toshiaki A. Furukawa, and Andrea Cipriani. 2008. "Effectiveness of Paroxetine in the Treatment of Acute Major Depression in Adults: A Systematic ReExamination of Published and Unpublished Data from Randomized Trials." CMAJ: Canadian Medical Association Journal = Journal de l'Association Medicale Canadienne 178 (3): 296-305.

Button, Katherine S., John P. A. Ioannidis, Claire Mokrysz, Brian A. Nosek, Jonathan Flint, Emma S. J. Robinson, and Marcus R. Munafò. 2013. "Power Failure: Why Small Sample Size Undermines the Reliability of Neuroscience." Nature Reviews. Neuroscience 14 (5): $365-76$.

Chong, Simon W., Neil F. Collins, Christine Y. Wu, Grace M. Liskaser, and Philip J. Peyton. 2016. "The Relationship between Study Findings and Publication Outcome in Anesthesia Research: A Retrospective Observational Study Examining Publication Bias." Canadian Journal of Anaesthesia = Journal Canadien D'anesthesie 63 (6): 682-90.

De Oliveira, Gildasio S., Jr, Ray Chang, Mark C. Kendall, Paul C. Fitzgerald, and Robert J. McCarthy. 2012. "Publication Bias in the Anesthesiology Literature." Anesthesia and Analgesia 114 (5): 1042-48.

Dickersin, K. 1990. "The Existence of Publication Bias and Risk Factors for Its Occurrence." JAMA: The Journal of the American Medical Association 263 (10): 1385-89.

Dirnagl, Ulrich, and Martin Lauritzen. 2010. "Fighting Publication Bias: Introducing the Negative Results Section." Journal of Cerebral Blood Flow and Metabolism: Official Journal of the International Society of Cerebral Blood Flow and Metabolism 30 (7): 126364.

Durinka, M. D., B. Joel, Tyler Wenzel, Christopher Ortiz, Lynn Choi, and Jorge Ortiz. 2016. "Fate of Abstracts Presented at the 2007-2009 Americas Hepato-Pancreato-Biliary Association Meetings." Translation: The University of Toledo Journal of Medical Sciences $3(1): 1$.

Easterbrook, P. J., J. A. Berlin, R. Gopalan, and D. R. Matthews. 1991. "Publication Bias in Clinical Research." The Lancet 337 (8746): 867-72.

Eloubeidi, M. A., S. B. Wade, and D. Provenzale. 2001. "Factors Associated with Acceptance and Full Publication of GI Endoscopic Research Originally Published in Abstract Form." Gastrointestinal Endoscopy 53 (3): 275-82.

Evangelou, Evangelos, Konstantinos C. Siontis, Thomas Pfeiffer, and John P. A. Ioannidis. 2012. "Perceived Information Gain from Randomized Trials Correlates with Publication in 
387

388

389

390

391

392

393

394

395

396

397

398

399

400

401

402

403

404

405

406

407

408

409

410

411

412

413

414

415

416

417

418

419

420

421

422

423

424

425

426

427

428

429

430

431

432

High-Impact Factor Journals.” Journal of Clinical Epidemiology 65 (12): 1274-81.

Eyding, Dirk, Monika Lelgemann, Ulrich Grouven, Martin Härter, Mandy Kromp, Thomas Kaiser, Michaela F. Kerekes, Martin Gerken, and Beate Wieseler. 2010. "Reboxetine for Acute Treatment of Major Depression: Systematic Review and Meta-Analysis of Published and Unpublished Placebo and Selective Serotonin Reuptake Inhibitor Controlled Trials." BMJ 341. British Medical Journal Publishing Group: c4737.

Fanelli, Daniele. 2010. "Do Pressures to Publish Increase Scientists' Bias? An Empirical Support from US States Data." PloS One 5 (4): e10271.

Frank, Rachel M., Gregory L. Cvetanovich, Michael J. Collins, Thomas A. Arns, Austin Black, Nikhil N. Verma, Brian J. Cole, and Brian Forsythe. 2017. "Publication Rates of Podium Versus Poster Presentations at the Arthroscopy Association of North America Meetings 2008-2012." Arthroscopy: The Journal of Arthroscopic \& Related Surgery: Official Publication of the Arthroscopy Association of North America and the International Arthroscopy Association 33 (1): 6-11.

Gupta, Yogendra Kumar, Meenakshi Meenu, and Prafull Mohan. 2015. "The Tamiflu Fiasco and Lessons Learnt." Indian Journal of Pharmacology 47 (1): 11-16.

Harris, Petra, Andrea Takeda, Emma Loveman, and Debbie Hartwell. 2010. "Time to Full Publication of Studies of Anticancer Drugs for Breast Cancer, and the Potential for Publication Bias." International Journal of Technology Assessment in Health Care 26 (1): 110-16.

Hedin, Riley J., Blake A. Umberham, Byron N. Detweiler, Lauren Kollmorgen, and Matt Vassar. 2016. "Publication Bias and Nonreporting Found in Majority of Systematic Reviews and Meta-Analyses in Anesthesiology Journals." Anesthesia and Analgesia 123 (4): 1018-25.

Hopewell, Sally, Kirsty Loudon, Mike J. Clarke, Andrew D. Oxman, and Kay Dickersin. 2009. "Publication Bias in Clinical Trials due to Statistical Significance or Direction of Trial Results." Cochrane Database of Systematic Reviews , no. 1 (January): MR000006.

Hopewell, S., M. Clarke, L. Stewart, and J. Tierney. 2007. "Time to Publication for Results of Clinical Trials." Cochrane Database of Systematic Reviews , no. 2 (April): MR000011.

Jefferson, Tom, Mark A. Jones, Peter Doshi, Chris B. Del Mar, Rokuro Hama, Matthew J. Thompson, Elizabeth A. Spencer, Igho J. Onakpoya, Kamal R. Mahtani, David Nunan, Jeremy Howick, Carl J. Heneghan 2014. "Neuraminidase Inhibitors for Preventing and Treating Influenza in Healthy Adults and Children." Cochrane Database of Systematic Reviews, no. 4 (April): CD008965.

Jones, Christopher W., Valerie A. Braz, Stephen M. McBride, Brian W. Roberts, and Timothy F. Platts-Mills. 2016. "Cross-Sectional Assessment of Patient Attitudes towards Participation in Clinical Trials: Does Making Results Publicly Available Matter?” BMJ Open 6 (11): $\mathrm{e} 013649$.

Jones, Philip M. 2016. "Publication Bias in the Anesthesiology Literature: Shifting the Focus from the 'Positive' to the 'Truth." Canadian Journal of Anaesthesia = Journal Canadien D'anesthesie 63 (6): 658-63.

Lim, Byung Gun, Il Ok Lee, Hyeongsik Ahn, Dong Kyu Lee, Young Ju Won, Hyun Jung Kim, and Heezoo Kim. 2016. "Comparison of the Incidence of Emergence Agitation and Emergence Times between Desflurane and Sevoflurane Anesthesia in Children: A Systematic Review and Meta-Analysis." Medicine 95 (38): e4927.

Mark, Daniel B., Kerry L. Lee, and Frank E. Harrell Jr. 2016. "Understanding the Role of P Values and Hypothesis Tests in Clinical Research.” JAMA Cardiology 1 (9): 1048-54. 
433

434

435

436

437

438

439

440

441

442

443

444

445

446

447

448

449

450

451

452

453

454

455

456

457

458

459

460

461

462

463

464

465

466

467

468

469

470

471

472

473

474

475

476

477

478

Masic, Izet, Milan Miokovic, and Belma Muhamedagic. 2008. "Evidence Based Medicine - New Approaches and Challenges." Acta Informatica Medica: AIM: Journal of the Society for Medical Informatics of Bosnia \& Herzegovina: Casopis Drustva Za Medicinsku Informatiku BiH 16 (4): 219-25.

Paulson, Kristjan, Mahwash Saeed, Jennifer Mills, Geoff D. E. Cuvelier, Rajat Kumar, Colette Raymond, Tracy Robinson, David Szwajcer, Donna Wall, and Matthew D. Seftel. 2011. "Publication Bias Is Present in Blood and Marrow Transplantation: An Analysis of Abstracts at an International Meeting." Blood 118 (25): 6698-6701.

Piccirillo, Jay F. 2016. "Improving the Quality of the Reporting of Research Results." JAMA Otolaryngology-- Head \& Neck Surgery 142 (10): 937-39.

Pierson, David J. 2004. "The Top 10 Reasons Why Manuscripts Are Not Accepted for Publication." Respiratory Care 49 (10): 1246-52.

Prendergast, Sarah, Katharina Mattishent, Tom Broughton, and Ian Beales. 2013. "Is Gastroenterology Research in Decline? A Comparison of Abstract Publication Rates from The British Society of Gastroenterology Meetings between 1995 and 2005." F1000Research 2 (February): 59.

Raju, Suneil A., David S. Sanders, Rahim Akram, Rebecca Glover, Ammar Al-Rifaie, Elise Peever, Josh Purves, Emily Scanu, and Matthew Kurien. 2017. "United European Gastroenterology Week Scientific Abstracts and Their Progression to Full Publication.” European Journal of Gastroenterology \& Hepatology 29 (10): 1136-40.

Sackett, D. L., W. M. Rosenberg, J. A. Gray, R. B. Haynes, and W. S. Richardson. 1996. "Evidence Based Medicine: What It Is and What It Isn't." BMJ 312 (7023): 71-72.

Saeed, Mahwash, Kristjan Paulson, P. Lambert, David Szwajcer, and Matthew Seftel. 2011. "Publication Bias in Blood and Marrow Transplantation." Biology of Blood and Marrow Transplantation: Journal of the American Society for Blood and Marrow Transplantation 17 (6): 930-34.

Salami, Khadra, and Khaldoun Alkayed. 2013. "Publication Bias in Pediatric Hematology and Oncology: Analysis of Abstracts Presented at the Annual Meeting of the American Society of Pediatric Hematology and Oncology." Pediatric Hematology and Oncology 30 (3): 16569.

Sartor, C. I., B. L. Peterson, and S. Woolf. 2003. "Time to Full Publication of Studies of Anticancer Drugs for Breast Cancer, and the Potential for Publication Bias." In Proc Am Soc Clin Oncol, 22:30-40.

Scherer, Roberta W., Cesar Ugarte-Gil, Christine Schmucker, and Joerg J. Meerpohl. 2015. "Authors Report Lack of Time as Main Reason for Unpublished Research Presented at Biomedical Conferences: A Systematic Review." Journal of Clinical Epidemiology 68 (7): 803-10.

Scherer, R. W., P. Langenberg, and E. von Elm. 2007. "Full Publication of Results Initially Presented in Abstracts." Cochrane Database of Systematic Reviews , no. 2 (April): MR000005.

Shaheen, N. J., M. A. Crosby, E. M. Bozymski, and R. S. Sandler. 2000. "Is There Publication Bias in the Reporting of Cancer Risk in Barrett's Esophagus?" Gastroenterology 119 (2): 333-38.

Song, Fujian, Yoon Loke, and Lee Hooper. 2014. "Why Are Medical and Health-Related Studies Not Being Published? A Systematic Review of Reasons given by Investigators." PloS One 9 (10): e110418. 
479

480

481

482

483

484

485

486

487

488

489

490

491

492

493

494

495

496

497

498

499

500

501

502

503

504

505

506

507

508

509

510

511

512

513

514
Sukhal, Shashvat, Jaskaran Sethi, Malini Ganesh, Pedro A. Villablanca, Anita K. Malhotra, and Harish Ramakrishna. 2017. "Extracorporeal Membrane Oxygenation in Severe Influenza Infection with Respiratory Failure: A Systematic Review and Meta-Analysis." Annals of Cardiac Anaesthesia 20 (1): 14-21.

Takeda, A., E. Loveman, P. Harris, D. Hartwell, and K. Welch. 2008. "Time to Full Publication of Studies of Anti-Cancer Medicines for Breast Cancer and the Potential for Publication Bias: A Short Systematic Review." Health Technology Assessment 12 (32): iii, ix - x, 146.

Tang, P. A., G. R. Pond, S. Welch, and E. X. Chen. 2014. "Factors Associated with Publication of Randomized Phase Iii Cancer Trials in Journals with a High Impact Factor." Current Oncology 21 (4): e564-72.

Timmer, Antje, Robert J. Hilsden, John Cole, David Hailey, and Lloyd R. Sutherland. 2002. "Publication Bias in Gastroenterological Research - a Retrospective Cohort Study Based on Abstracts Submitted to a Scientific Meeting." BMC Medical Research Methodology 2 (April): 7.

Turner, Erick H., Annette M. Matthews, Eftihia Linardatos, Robert A. Tell, and Robert Rosenthal. 2008. "Selective Publication of Antidepressant Trials and Its Influence on Apparent Efficacy." The New England Journal of Medicine 358 (3): 252-60.

Wasserstein, Ronald L., and Nicole A. Lazar. 2016. "The ASA's Statement on P-Values: Context, Process, and Purpose." The American Statistician 70 (2). Taylor \& Francis: 12933.

Whittington, Craig J., Tim Kendall, Peter Fonagy, David Cottrell, Andrew Cotgrove, and Ellen Boddington. 2004. "Selective Serotonin Reuptake Inhibitors in Childhood Depression: Systematic Review of Published versus Unpublished Data.” The Lancet 363 (9418): 134145.

Wolfenden, Luke, Anna Ziersch, Priscilla Robinson, John Lowe, and John Wiggers. 2015. "Reducing Research Waste and Improving Research Impact." Australian and New Zealand Journal of Public Health 39 (4): 303-4. 


\section{Table 1 (on next page)}

Study design of abstracts and number that reached publication 
1 Table 1 Study design of abstracts and number that reached publication

\begin{tabular}{|c|c|c|c|}
\hline Study Design & $\begin{array}{l}\text { Abstracts by } \\
\text { study type (n) }\end{array}$ & $\begin{array}{l}\text { Abstracts reporting a } \\
\text { significant } \mathrm{P} \text { value by study } \\
\text { type (n) }\end{array}$ & $\begin{array}{l}\text { Abstracts reaching } \\
\text { publication by study type } \\
\text { (n) }\end{array}$ \\
\hline $\begin{array}{l}\text { Randomized } \\
\text { Controlled Trials }\end{array}$ & 3 & 2 & $3(100 \%)$ \\
\hline Cohort & 17 & 8 & $11(64.7 \%)$ \\
\hline $\begin{array}{l}\text { Retrospective } \\
\text { Analysis }\end{array}$ & 313 & 183 & $150(47.9 \%)$ \\
\hline Case Report & 58 & 1 & $12(20.7 \%)$ \\
\hline Video Report & 14 & 0 & $3(21.4 \%)$ \\
\hline Survey Report & 8 & 5 & $2(25 \%)$ \\
\hline Basic Science & 29 & 15 & $11(37.9 \%)$ \\
\hline Single Assignment & 19 & 5 & $11(57.9 \%)$ \\
\hline $\begin{array}{l}\text { Systematic } \\
\text { Review/Meta- } \\
\text { Analysis }\end{array}$ & 7 & 3 & $2(86.5 \%)$ \\
\hline Prospective Analysis & 40 & 24 & $23(57.5 \%)$ \\
\hline Animal Study & 16 & 8 & $8(50 \%)$ \\
\hline Cost Analysis & 3 & 0 & $2(66.7 \%)$ \\
\hline Technique Report & 42 & 0 & $5(11.9 \%)$ \\
\hline
\end{tabular}

2 
Table 2 (on next page)

Journals responsible for publishing abstracts 
1 Table 2 Journals responsible for publishing abstracts

2

\begin{tabular}{|c|c|c|c|c|}
\hline Journal & $\begin{array}{l}\text { Abstracts } \\
\text { published } \\
\text { (n) }\end{array}$ & $\begin{array}{l}\text { Abstracts with } \\
\text { significant } \\
\text { outcome (n) }\end{array}$ & $\begin{array}{l}\text { Abstracts } \\
\text { with negative } \\
\text { outcome (n) }\end{array}$ & $\begin{array}{l}\text { Abstracts with no } \\
\text { reported P value } \\
\text { reaching } \\
\text { publication (n) }\end{array}$ \\
\hline $\begin{array}{l}\text { American Journal of } \\
\text { Transplantation }\end{array}$ & 1 & 1 & 0 & 0 \\
\hline Annals of Surgery & 5 & 4 & 0 & 1 \\
\hline Annals of Surgical Oncology & 14 & 8 & 0 & 6 \\
\hline Annals of Vascular surgery & 1 & 1 & 0 & 0 \\
\hline Archives of Surgery & 1 & 1 & 0 & 0 \\
\hline $\begin{array}{l}\text { Arquvois Brasileiros De } \\
\text { Cirurgia Digestiva }\end{array}$ & 1 & 0 & 0 & 1 \\
\hline BMC Cancer & 2 & 1 & 0 & 1 \\
\hline British Journal of Surgery & 1 & 1 & 0 & 0 \\
\hline Canadian Journal of Surgery & 1 & 1 & 0 & 0 \\
\hline Cancer & 1 & 0 & 0 & 1 \\
\hline Cancer Biology \& Therapy & 1 & 0 & 0 & 1 \\
\hline Cancer Investigation & 1 & 1 & 0 & 0 \\
\hline Clinical Transplantation & 2 & 1 & 0 & 1 \\
\hline Diagnostics & 1 & 1 & 0 & 0 \\
\hline Endoscopy & 1 & 0 & 0 & 1 \\
\hline $\begin{array}{l}\text { European Journal of Surgical } \\
\text { Oncology }\end{array}$ & 2 & 1 & 0 & 1 \\
\hline $\begin{array}{l}\text { European Journal of Trauma } \\
\text { and Emergency Surgery }\end{array}$ & 1 & 0 & 1 & 0 \\
\hline European Surgical Research & 1 & 0 & 0 & 1 \\
\hline Genetics in Medicine & 1 & 0 & 1 & 0 \\
\hline $\begin{array}{l}\text { Hepatobiliary \& Pancreatic } \\
\text { Diseases International }\end{array}$ & 2 & 0 & 0 & 2 \\
\hline Hepatogastroenterology & 2 & 1 & 0 & 1 \\
\hline HPB & 115 & 74 & 7 & 34 \\
\hline $\begin{array}{l}\text { International Journal of } \\
\text { Hyperthermia }\end{array}$ & 1 & 0 & 0 & 1 \\
\hline $\begin{array}{l}\text { International Journal of } \\
\text { Surgery }\end{array}$ & 2 & 2 & 0 & 0 \\
\hline
\end{tabular}




\begin{tabular}{|c|c|c|c|c|}
\hline $\begin{array}{l}\text { International Journal of } \\
\text { Surgical Oncology }\end{array}$ & 2 & 1 & 1 & 0 \\
\hline JAMA Surgery & 1 & 1 & 0 & 0 \\
\hline $\begin{array}{l}\text { Journal of Biomedical } \\
\text { Materials Research }\end{array}$ & 1 & 0 & 0 & 1 \\
\hline $\begin{array}{l}\text { Journal of Clinical } \\
\text { Investigation }\end{array}$ & 1 & 0 & 0 & 1 \\
\hline $\begin{array}{l}\text { Journal of Gastrointestinal } \\
\text { Cancer }\end{array}$ & 1 & 1 & 0 & 0 \\
\hline $\begin{array}{l}\text { Journal of Gastrointestinal } \\
\text { Surgery }\end{array}$ & 12 & 8 & 0 & 4 \\
\hline $\begin{array}{l}\text { Journal of Hepato-biliary- } \\
\text { pancreatic Sciences }\end{array}$ & 1 & 0 & 0 & 1 \\
\hline $\begin{array}{l}\text { Journal of Liver: Disease and } \\
\text { Transplantation }\end{array}$ & 1 & 0 & 0 & 1 \\
\hline $\begin{array}{l}\text { Journal of Laparoendoscopic } \\
\text { \& Advanced Surgical } \\
\text { Techniques }\end{array}$ & 2 & 0 & 0 & 2 \\
\hline Journal of microwave surgery & 1 & 0 & 0 & 1 \\
\hline Journal of Robotic surgery & 1 & 0 & 0 & 1 \\
\hline Journal of Surgical Oncology & 7 & 5 & 0 & 2 \\
\hline Journal of Surgical Research & 2 & 0 & 1 & 1 \\
\hline Journal of Surgical Resection & 2 & 1 & 0 & 1 \\
\hline $\begin{array}{l}\text { Journal of the American } \\
\text { College of Surgeons }\end{array}$ & 6 & 4 & 0 & 2 \\
\hline $\begin{array}{l}\text { Journal of the Medical } \\
\text { Association of Thailand }\end{array}$ & 1 & 0 & 0 & 1 \\
\hline $\begin{array}{l}\text { Journal of the Society of } \\
\text { Laparoendoscopic Surgeons }\end{array}$ & 3 & 0 & 0 & 3 \\
\hline $\begin{array}{l}\text { Langenbeck's Archives of } \\
\text { Surgery }\end{array}$ & 1 & 1 & 0 & 0 \\
\hline Liver Transplantation & 1 & 1 & 0 & 0 \\
\hline Molecular Oncology & 1 & 0 & 0 & 1 \\
\hline Neoplasia & 1 & 1 & 0 & 0 \\
\hline $\begin{array}{l}\text { Open Journal of Organ } \\
\text { Transplant Surgery }\end{array}$ & 1 & 0 & 0 & 1 \\
\hline Pediatric Transplantation & 1 & 0 & 1 & 0 \\
\hline PLOS one & 2 & 0 & 1 & 1 \\
\hline
\end{tabular}




\begin{tabular}{|l|r|r|r|r|}
\hline Radiology Society of North & 1 & 1 & 0 & 0 \\
\hline America & 1 & 1 & 0 & 0 \\
\hline Seminars in Liver Disease & 5 & 3 & 0 & 2 \\
\hline Surgery & 6 & 3 & 0 & 3 \\
\hline Surgical Endoscopy & 2 & 1 & 0 & 1 \\
\hline Surgical Innovation & 4 & & & 1 \\
\hline $\begin{array}{l}\text { The American Journal of } \\
\text { Surgery }\end{array}$ & 2 & 3 & 0 & 1 \\
\hline The American Surgeon & 2 & 0 & 1 & 0 \\
\hline Transplantation Proceedings & 3 & 1 & 1 & 2 \\
\hline $\begin{array}{l}\text { World Journal of } \\
\text { Gastroenterology }\end{array}$ & & & & 0 \\
\hline $\begin{array}{l}\text { World Journal of } \\
\text { Gastrointestinal } \\
\text { Pathophysiology }\end{array}$ & & & & \\
\hline $\begin{array}{l}\text { World Journal of Surgical } \\
\text { Oncology }\end{array}$ & & & & \\
\hline
\end{tabular}

3 
Figure 1 (on next page)

Flow diagram for locating articles 
First author searches Google then Google Scholar then PubMed using presentation title.

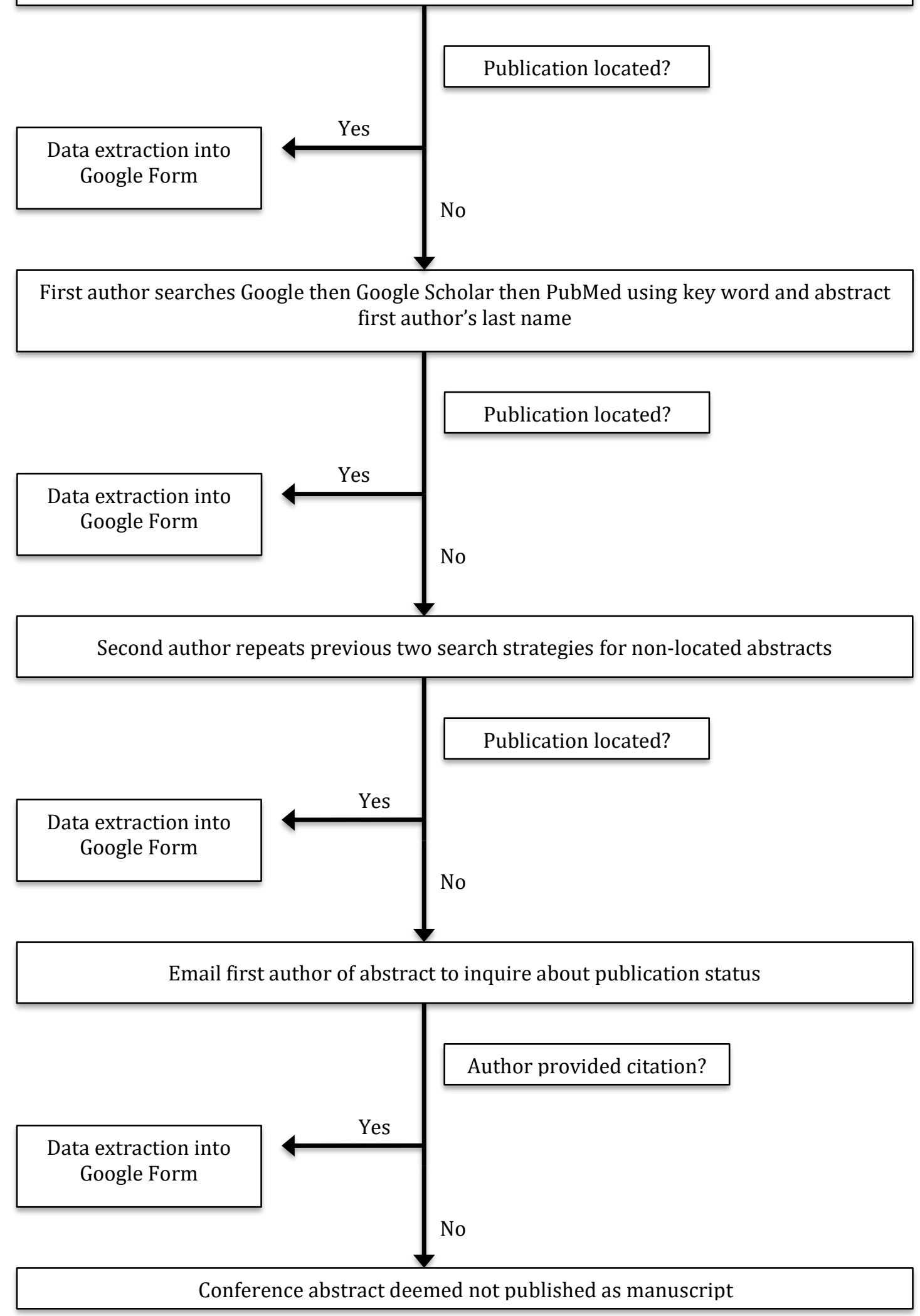


Figure 2 (on next page)

Flow diagram outlining search results 


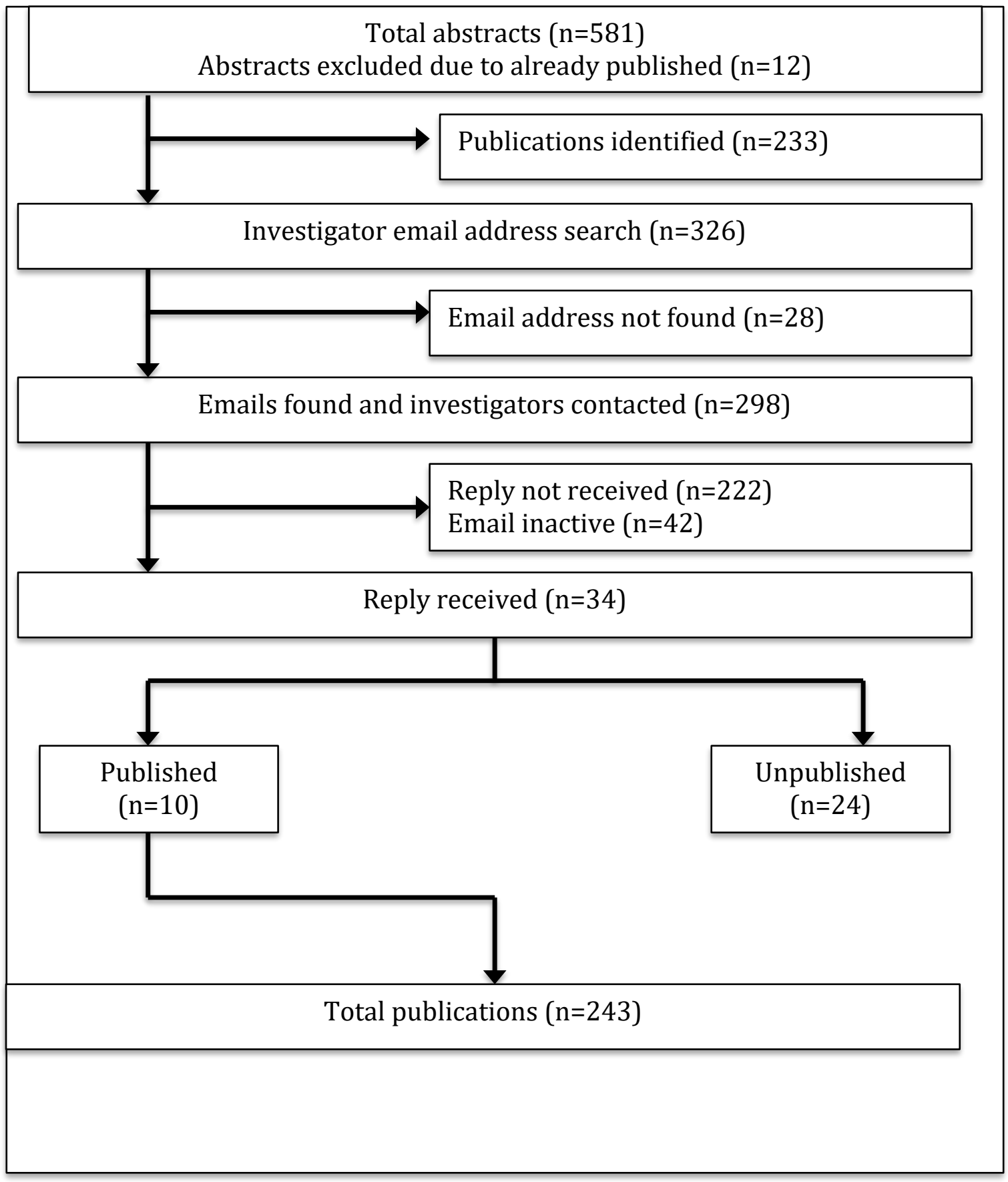


Figure 3

Cumulative rate of publication

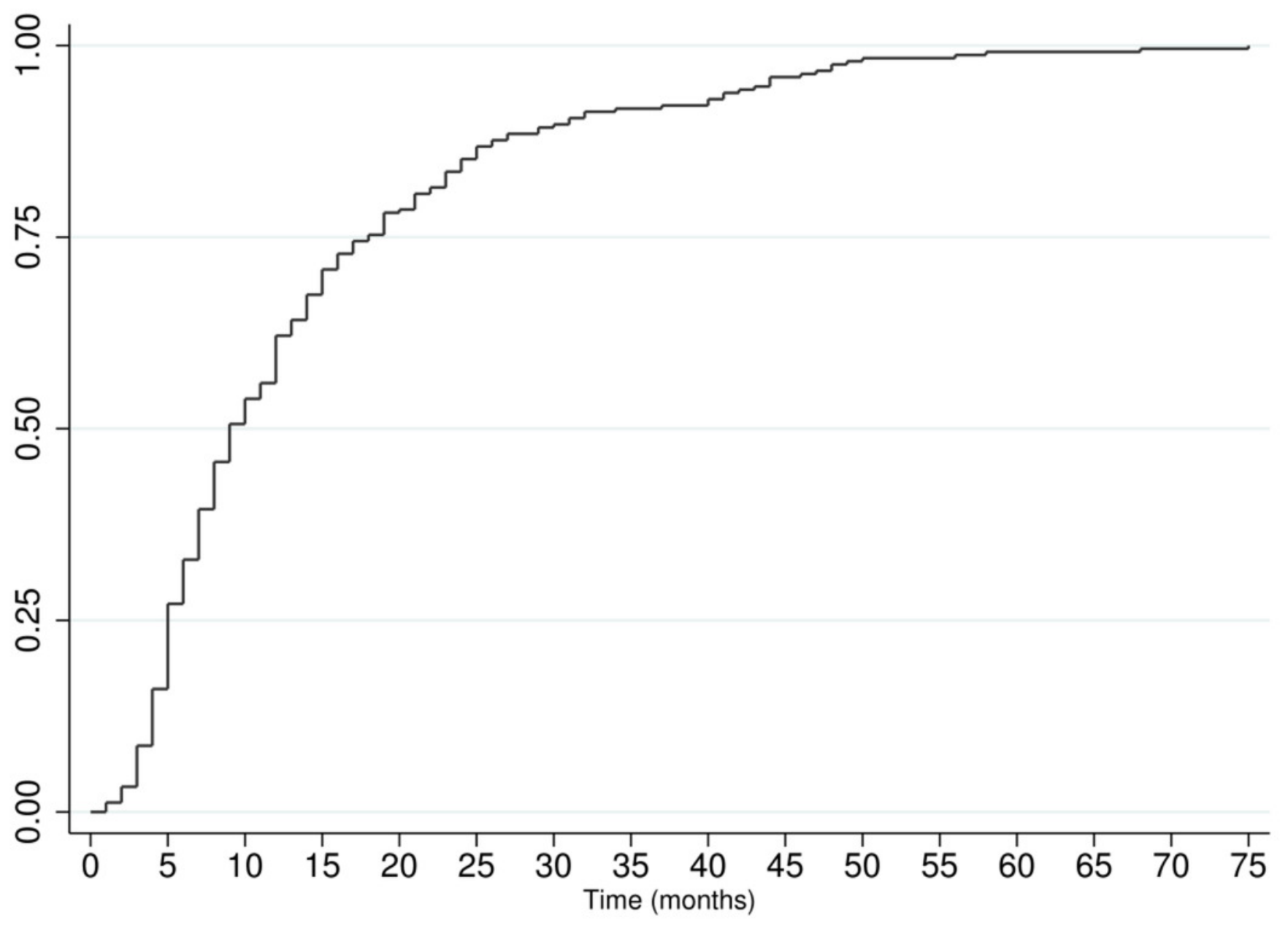

